\title{
Numerical analysis of stress distribution generated in spherical polyethylene inserts by knee joint endoprotheses' sleds
}

\author{
Marcin Nabrdalik, Michał Sobociński* \\ Czestochowa University of Technology, Faculty of Mechanical Engineering and Computer Science, Al. Armii Krajowej 21, \\ 42-217 Częstochowa, Poland \\ "Corresponding author: e-mail: sobocinski@iop.pcz.pl
}

\begin{abstract}
The paper presents analysis of stress distribution in the friction node of knee joint endoprosthesis where sleds are made of various titanium alloys and CoCrMo cooperate with spherical polyethylene inserts. Currently used titanium alloys consists of $\mathrm{Nb}, \mathrm{Ta}, \mathrm{Zr}$ or Mo and with lesser value of Young's modulus than Ti6Al4V alloy, or steel $\mathrm{CoCrMo}$, which significantly varies from other metal materials. The obtained results make it possible to indicate the "weak points" of the accepted solution, and thus counteract the subsequent effects resulting from premature wear of endoprosthesis elements. The analysis was conducted with numerical method of ADINA System 8.6. The Finite Elements Method allowed to compute and present stress distribution quickly in all elements of the model.
\end{abstract}

Keywords: polyethylene UHMWPE, FEM, endoprosthesis of knee joint.

\section{INTRODUCTION}

The aim of the paper is to analyse the state of stresses occurring in the contact surface of metal sleds cooperating with spherical polyethylene inserts in Motte - Calle's knee joint endoprosthesis. The analysis is to define optimal material for sleds construction in order to stress distribution on the polyethylene insert's surface was most advantegous and even. Thanks to finite elements method it is possible to define values of the stress in friction nodes in knee joint endoprostheses with all types of sleds and polyethylene inserts subjected to any loads. That way of analysis allows quickly obtain legible maps of stress and values for numerous models of similar endoprostheses without additional costs of their physical construction. Numerical analysis also helps to prepare and optimize construction of endoprosthesis. The most problematic for endoprostheses constuctors are contact stress of movable elements of endoprostheses and wear processes, which can be reduced by properly adjusted joint artificial surfaces. As polyethylene has lower strength features than metal sleds of the implant, it requires inserts of properly adjusted shape decreasing the wear. The best shape is still being looked for, the geometry of the insert is still under elaboration in order to increase durability of the implant ${ }^{7,8,9,10}$.

Currently applied polyethylene inserts can be divided into 2 groups: (1) flat and (2) spherical. Figure 1 presents both geometrical solutions of polyethylene inserts.

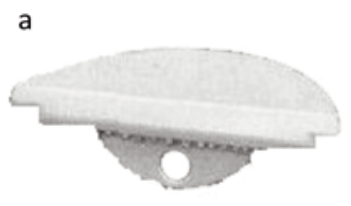

b

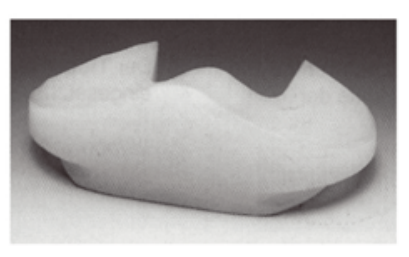

Figure 1. Polyethylene inserts: a) flat, b) spherical

The shape of inserts is still under discussion because of many important usage, assembly and strength issues, which may affect durability of endoprostheses, ${ }^{1,2}$. One option stands for flat inserts, supported by doctors and constructors as it allows some mistakes of the surgeon as far as positioning of both parts of endoprosthesis during implantation are concerned. The opponents claim that unit pressures in such constructions are high and may lead to delamination of the material and effect in rapid wear. Those in favour of spherical inserts and metal sleds emphasise that in this construction stress distribution is on approvable level, however they admit that their assembling is more complex and difficult.

In the group of metal materials used for implants, the focus is on low Young and low density. Such features has titanium and its alloys especially with niobium ${ }^{3,4}$.

There are currently conducted tests on titanium alloys with niobium zircon with much lower elasticity modulus of 55-60 GPa. Titanium alloys Ti6Al4V as well as new generation alloys TiNbZr i TiNbZrTa have very good mechanical features, however lower elasticity modulus of the alloys with niobium shows that such alloys are the future of alloplasty.

Low value of Young modulus in new titanium alloys can assure lower value of generated stresses in polyethylene inserts cooperating with metal sleds as well as better performance between stem and bone ${ }^{11-15}$.

\section{ANALYSIS OF THE STRESS IN THE PAIR SLED - SPHERICAL INSERT IN MOTTE CALLE'S ENDO- PROSTHESIS}

The calculations were conducted for partial endoprosthesis with spherical polyethylene insert. They defined reduced and contact stresses occurring in polyethylene inserts cooperating with metal sleds made of various titanium alloys and CoCrMo. Polyethylene UHMWPE is the weakest point of the endoprosthesis, that is why it is important to present the reduced stress distribution in the inserts.

To analyze the achieved results, the following formulas have been chosen. Formula (1) presents physical equations connecting stress and strain tensors' values in $3 \mathrm{D}$, in isotropic, linear - elastic ${ }^{5}$.

$$
\begin{array}{r}
\sigma_{x}=\frac{E}{1+v}\left[\varepsilon_{x}+\frac{v}{1-2 v}\left(\varepsilon_{x}+\varepsilon_{y}+\varepsilon_{z}\right)\right] \\
\sigma_{y}=\frac{E}{1+v}\left[\varepsilon_{y}+\frac{v}{1-2 v}\left(\varepsilon_{x}+\varepsilon_{y}+\varepsilon_{z}\right)\right] \\
\sigma_{z}=\frac{E}{1+v}\left[\varepsilon_{z}+\frac{v}{1-2 v}\left(\varepsilon_{x}+\varepsilon_{y}+\varepsilon_{z}\right)\right]
\end{array}
$$


Material constants:

E - Young's modulus (elasticity)

G - Kirchoff's modulus (non-dilatational strain)

$v$ - Poisson's coefficient

By solving the equation, we can define components of the stress as a function of the strain.

The durability of endoprosthesis depends on mechanical and tribological features of its weakest element, which is polyethylene insert. Reduced stresses are usually normal substitute stress, compared to material strength during one-axis extension. The reduced stresses depend on all stress tensor's components, and are presented by formula $^{5,18}(2)$ :

$$
\begin{array}{r}
\sigma_{\text {red }}=f\left(\sigma_{x x}, \sigma_{y y}, \sigma_{z z}, \tau_{x y}, \tau_{x z}, \tau_{z y}\right) \\
\text { lub } \sigma_{\text {red }}=f\left(\sigma_{11}, \sigma_{22}, \sigma_{33}\right),
\end{array}
$$

where:

$\sigma_{11}, \sigma_{22}, \sigma_{33}-$ main stress

$\sigma_{\text {red }}$ - Huber - Mises's reduced stress

Huber - Mises's strength hypothesis, presents the formula (3).

$$
\sigma_{\text {red }}=\frac{1}{\sqrt{2}} \sqrt{\left(\sigma_{11}-\sigma_{22}\right)^{2}+\left(\sigma_{33}-\sigma_{22}\right)^{2}+\left(\sigma_{11}-\sigma_{33}\right)^{2}}
$$

or

$$
\sigma_{r e d} Q \mathbb{x} \frac{1}{\sqrt{2}} \sqrt{\left(\sigma_{x x}-\sigma_{y y}\right)^{2}+\left(\sigma_{z z}-\sigma_{y y}\right)^{2}+\left(\sigma_{x x}-\sigma_{z z}\right)^{2}+6\left(\tau_{x y}{ }^{2}+\tau_{y z}{ }^{2}+\tau_{x z}{ }^{2}\right)}
$$

\section{MOTTE - CALLE'S KNEED JOINT ENDOPROSTHE- SIS}

Figure 2 presents very commonly used knee joint endoprosthesis by Motte - Calle, with optimally adjusted elements (sled - spherical polyethylene insert) as far as movability of the joint is concerned. Thigh part images its condyles. It is precisely fixed with two pins and stem ${ }^{\mathbf{1 6}, \mathbf{1 7}}$.

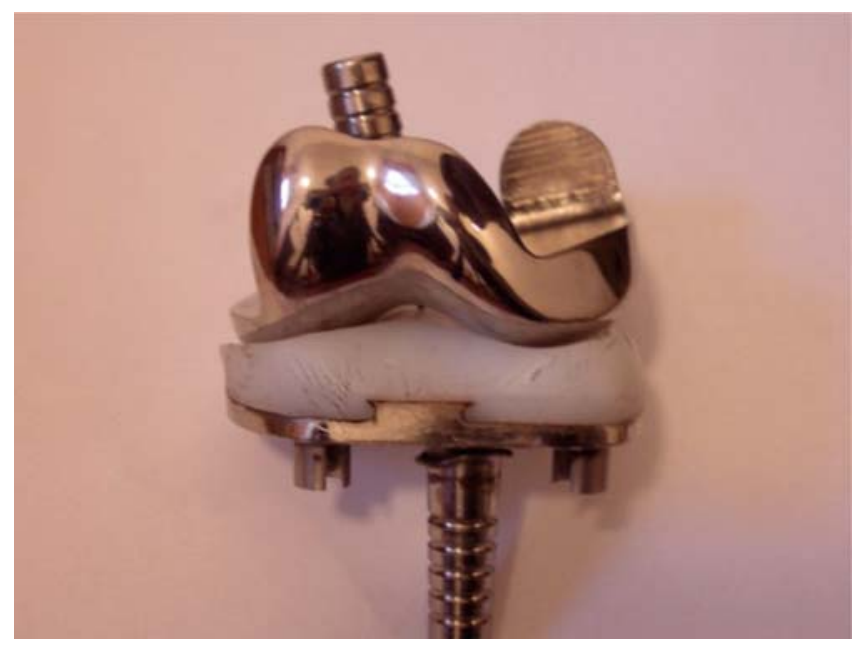

Figure 2. Endoprosthesis Motta-Calle'a

Finite elements mesh taken for calculations consisted of 3600 hexahedronal 3D Solid elements and 4312 nodes. The model was represented by 12936 degrees of freedom. Numerical model is simplified one of endoprostheses, however sleds geometry has been maintained according to original dimensions. That gives general shape of endoprostheses and allows to image stress distribution on the insert surface. Figure 3 presents simplified numerical model of sled and insert ${ }^{19,20}$.

The model consists of metal sled, polyethylene insert and metal support in which the insert is fixed.

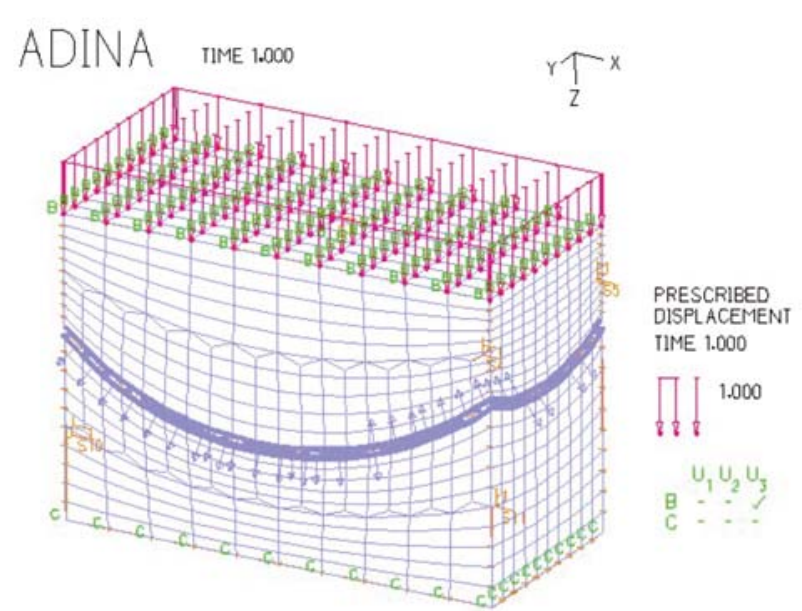

Figure 3. Numerical model of the set sled - spherical polyethylene insert. Finite elements mesh, load, degrees of freedom and contact area. General view

Numerical analysis was to define values of the reduced stresses and strain that occurr in polyethylene inserts when subjected to loads caused by sleds.

Material used in this kind of endoprostheses are: (1) metal alloy - thigh and tibia and (2) UHMWPE - insert. It is most commonly used pair of materials. Endoprostheses producers use many kinds of titanium alloys as it has very good mechanical parameters and lower density than CoCrMo alloys.

\section{CRITERIA TAKEN FOR NUMERICAL CALCULA- TIONS}

Theoretical criteria for contact stress according to Hertz's theory have been applied as follows:

- contacting elements are made of homogeneous isotropic materials and Hooke's law wise,

- the surfaces are fixed in the contact area of the element with smooth and regularly curved surfaces,

- when subjected to load there are only slight strains in the contact area,

- the contact area is relatively small when compared with the surfaces of the contacting elements,

- on the contact area there only occur normal strains.

The main purpose of the calculations is to define stress distribution on the surface of the polyethylene insert and right underneath it, where the sleds cooperate. There were three heights of polyethylene inserts analyzed: 8, 13 and $22 \mathrm{~mm}$, and two sleds of cross section radiuses of 17 and $27 \mathrm{~mm}$, respectively. The analyzed sleds were made of CoCrMo, Ti6Al4V, Ti13Nb13Zr, Ti12Mo6Zr2Fe, TiNbZrTa.

Thirty numerical analysis have been conducted for three various thicknesses of polyethylene inserts cooperating with two geometrically different sleds made of five different alloys. Each pair was subjected to load $\mathrm{F}=$ 1500 N. Simulations of the cases were conducted with the following, accepted physical features of the materials presented in the Table 1.

\section{THE RESULTS OF NUMERICAL ANALYSIS BY FINI- TE ELEMENTS METHOD AND ADINA SYSTEM 8.6}

The calculations prove that stress is concentrated in the polyethylene insert. right underneath the contact 
Table 1. Mechanical properties and density of endoprostheses materials ${ }^{\mathbf{6}}$

\begin{tabular}{|l|c|c|c|}
\hline & Young's modulus & Poisson's coefficient $v$ & $\begin{array}{c}\text { Density } \\
{\left[\begin{array}{l}\left.\mathrm{Eg} / \mathrm{m}^{3}\right] \\
\end{array}\right.}\end{array}$ \\
\hline CoCrMo $[\mathrm{GPa}]$ & 210 & 0.29 & 8300 \\
\hline Ti6Al4V & 110 & 0.3 & 4500 \\
\hline Ti13Nb13Zr & 80 & 0.3 & 4510 \\
\hline Ti12Mo6Zr2Fe & 73 & 0.3 & 4510 \\
\hline Ti NbZrTa & 53 & 0.3 & 4490 \\
\hline UHMWPE & 0.01 & 0.4 & 960 \\
\hline
\end{tabular}

area of both elements. and highest stress is located right underneath the insert's surface. Some examples of the calculations present figures 4 and 5 .

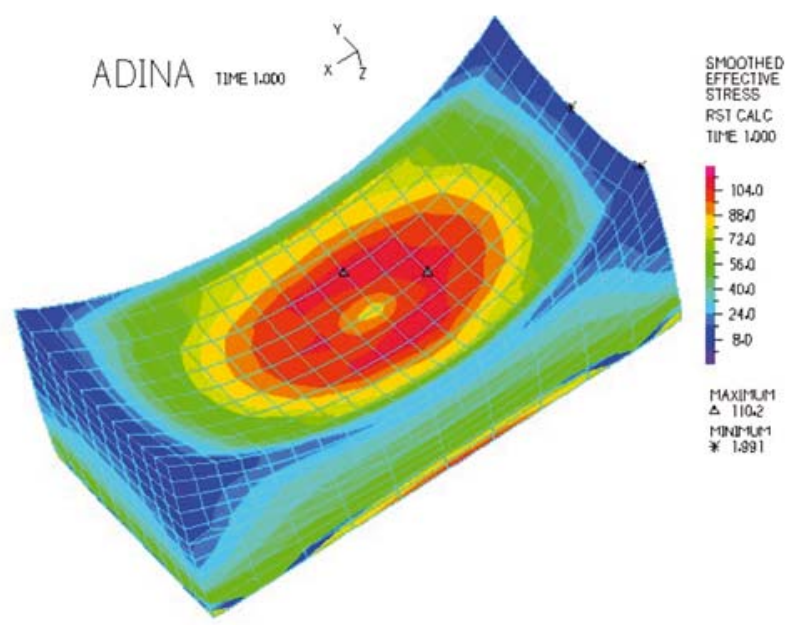

Figure 4. Contact stress pattern in the spherical polyethylene insert. General view of the model. The insert is $8 \mathrm{~mm}$ thick and cooperates with the sled of radius $27 \mathrm{~mm}$. Load $1500 \mathrm{~N}$

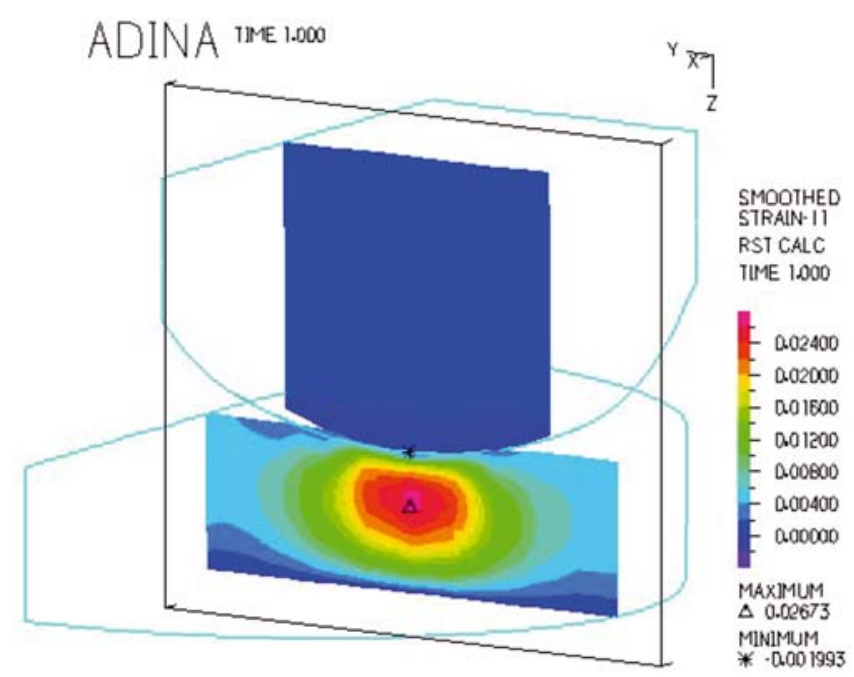

Figure 5. Material strain distribution occurring in sub-surfaces of spherical polyethylene insert cooperating with metal sled. Cross section of the model. Sled of cross section radius $27 \mathrm{~mm}$. Load $1500 \mathrm{~N}$

\section{REMARKS ON THE RESULTS OF CALCULATIONS}

The lowest reduced stress was achieved for the model where the sled's cross-section radius is $27 \mathrm{~mm}$. and the sled is made of TiNbZrTa alloy and valued 9.29 [MPa]. The highest stress occurred in the model where the sled was made of CoCrMo alloy. and valued 38.85 [MPa]. and the sled's cross section radius was smallest and valued $17 \mathrm{~mm}$. Figure 6 presents the influence of the cross section radius of the sled. thickness of the insert and kind of material which the sled is made of. on the value of the stress generated in the polyethylene insert.

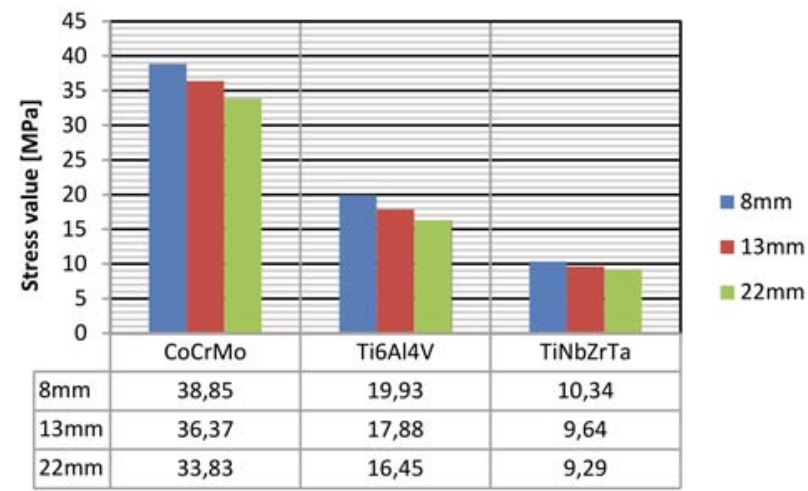

Figure 6. The influence of the sled's cross section radius and insert's thickness on the value of generated stress in the UHMWPE insert

\section{WEAR OF POLYETHYLENE ELEMENTS OF KNEE JOINT ENDOPROSTHESES COOPERATING WITH SLEDS. DURING LABORATORY TESTS}

Some important information about wear processes of friction elements of endoprostheses. may be delivered by research carried out on a special simulator. The research allow to assign the wear curves traces and to determine the wear of the tested material. in this case - polyethylene cooperating with sleds made of $\mathrm{CoCrMo}$ steel and several kinds of titanium alloys. The researches were carried out on a simulator imitating characteristic movements of a human leg. invented. constructed and assembled in Institute of Metal Working. Quality Engineering and Bioengineering. Faculty of the Mechanical Engineering and Computer Sciences. Częstochowa University of Technology. Laboratory tests were conducted for different load values $(800 \mathrm{~N} .1200 \mathrm{~N} .1500 \mathrm{~N})$. and carried out on the knee joint simulator used endoprostheses sleds of Motta - Calle.

Figure 7 presents the front view of the research station for testing durability of human knee joint endoprostheses .

Figure 8 presents an exemplary influence of the load of Motta-Calle's total knee endoprosthesis on average value of linear wear of a polyethylene insert.

Though in the friction pair "metal - polyethylene" the latter is less abrasion resistant. all metal elements get worn producing wear products. They cause so called "matalosis" phenomenon. which means the transfer of elements into surrounding tissues as a result of biological corrosion. what may cause several diseases or can even be carcinogenic. In order to decrease wear of polyethylene and metal elements. in this case the sleds 


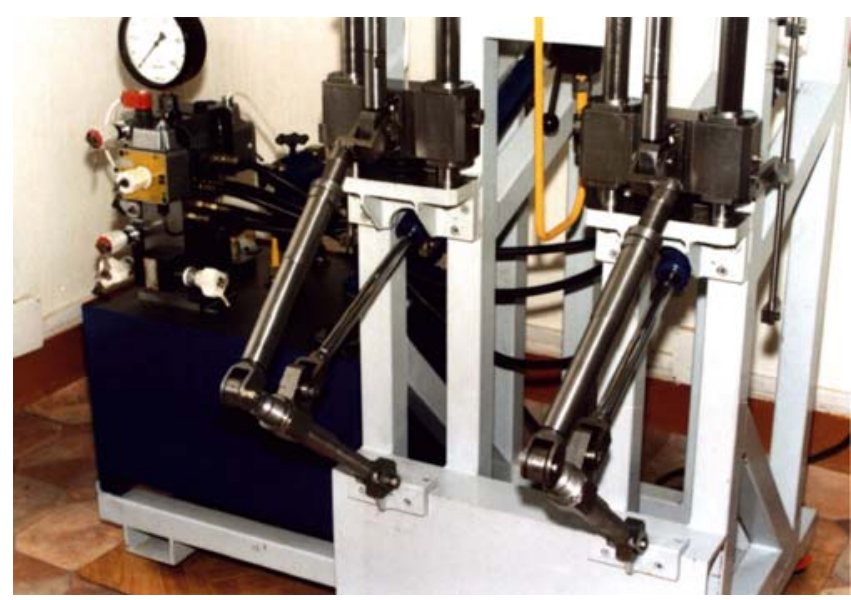

Figure 7. The front view of the research station for testing durability of human knee joint endoprostheses

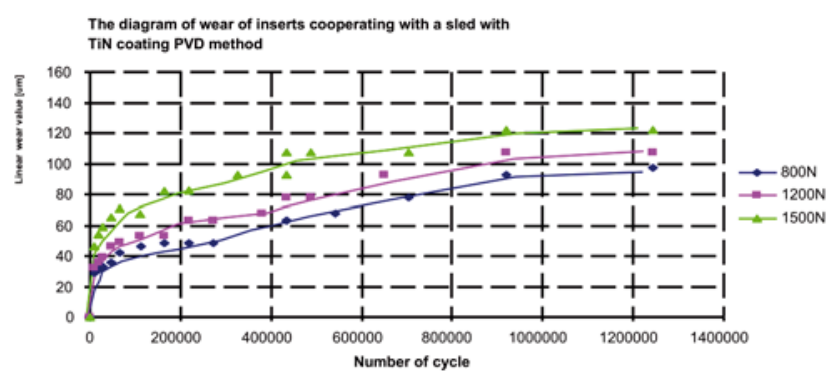

Figure 8. Influence of load force on linear wear value of the polyethylene insert. Measurements carried out for a Motta-Calle total knee endoprosthesis

of knee joint endoprostheses. all metal friction surfaces are covered with special layers by means of different methods. Covering with layers all metal surfaces directly within friction nodes. clearly restrains the number of metal and polyethylene wear products.

Durability of knee and hip joints endoprostheses is constrained by their weakest element - polyethylene component. If polyethylene's surface layer is modified. its friction wear resistance definitely increases.

Polyethylene that is actually used in medicine has quite poor tribological features. that is why some methods of its surface improvements. are being searched.

If UHMWPE polyethylene's surface layer is modified. the wear process is about $20 \%$ slower.

Evaluation of tribological features of materials used for producing elements of endoprostheses should be based on friction - wear research conducted on simulators of particular type of endoprosthesis work.

\section{CONCLUSIONS}

Durability of endoprosthesis is constituted by its weakest element. which is polyethylene insert.

Construction of endoprosthesis highly affects wear of polyethylene insert. especially its thickness. radius of metal sled as well as type of applied insert: flat or spherical.

Conducted numerical tests prove that the future of knee joints alloplasty belongs to new group of materials such as titanium alloys. which when mechanically properly adjusted (low value of Young modulus) may cause decrease of generated stresses in polyethylene elements of endoprosthesis.

Decrease of contact stresses can be obtained by proper adjustment of cooperating surfaces and substituting linear contact by spherical one. For insert adjusted to the sled with cross section radius $=27 \mathrm{~mm}$ generated pressures are better than for the sled with cross section radius $=17 \mathrm{~mm}$.

\section{LITERATURE CITED}

1. Gierzyńska-Dolna, M. (2002). Biotribology. Częstochowa. Publishing of Czestochowa University of Technology.

2. Gierzyńska-Dolna, M. \& Kubacki, J. (1999). Specificity of wear of hip and knee endoprostheses. Materials of II Symposium of Engineering Orthopedics and Protetics. IOP'99 Białystok. 45-51.

3. Gierzyńska-Dolna, M. (1997). Tribological problems in natural and artificial human joint. Biomaterials Engineering. 2/1997.

4. Long, M. \& Rack, H.J. (1998). Titanium alloys in total joint replacement - a materials science perspective. Biomaterials. 19 (1998) 1621-1639.

5. Zienkiewicz, O.C. (1972). Finite Elements Method. Publishing Arkady.

6. Marciniak, J. (2002). Biomaterials. Gliwice. Publishing of Silesian University of Technology.

7. Dygut, J. \& Kuchta, M. (2015). Research on dynamics of the knee joint for different types of loads. Bio-Algorithms and Med-Systems. 11. 4. DOI: 10.1515/bams-2015-0022.

8. Olinski, M., Gronowicz, A., Handke, A. \&Ceccarelli, M. (2016). Design and characterization of a novel knee articulation mechanism. Internati. J. Appl. Mech. Engine. 21. 3. DOI: 10.1515/ijame-2016-0037.

9. Dathe, H., Gezzi, R., Fiedler, Ch., Kubein-Meesenburg, D. \& Nägerl, H. (2016). The description of the human knee as four-bar linkage. Acta of Bioengin. Biomech. 18. 4. DOI: 10.5277/ ABB-00464-2015-03.

10. Nagerl, H., Dathe, H., Fiedler, Ch., Gowers, L., Kirsch, S., Kubein-Meesenburg, D., Dumont, C. \& Wachowski, M.M. (2015). The morphology of the articular surfaces of biological knee joints provides essential guidance for the construction of functional knee endoprostheses. Acta of Bioengine. Biomech. 17. 2. DOI: 10.5277/ABB-00119-2014-02.

11. Mielińska, A., Czamara, A., Szuba, Ł. \& Będziński, R. (2015) Biomechanical characteristics of the jump down of healthy subjects and patients with knee injuries. Acta of Bioengineering and Biomechanics. 17. 2. DOI: 10.5277/ABB00208-2014-04.

12. Ciszkiewicz, A. \& Knapczyk, J. (2014) Parameters estimation for the spherical model of the human knee joint using vector method. Internat. J. Appl. Mech. Engine. 19. 3. DOI: 10.2478/ijame-2014-0035.

13. Hajduk, G., Nowak, K., Sobota, G., Kusz, D., Kopeć, K., Błaszczak, E., Cieliński, Ł. \& Bacik, B. (2016). Kinematic gait parameters changes in patients after total knee arthroplasty: Comparison between cruciate-retaining and posterior-substituting design. Acta of Bioenginee. Biomech. 18. 3. DOI: 10.5277/ ABB-00405-2015-03.

14. Melzer, P., Głowacki, M., Głowacki, J. \& Misterska, E. (2014). Isokinetic evaluation of knee joint flexor and extensor muscles after tibial eminence fractures. Acta of Bioengine. Biomech. 16. 3. DOI: 10.5277/abb140313.

15. Knapczyk, J. \& Góra-Maniowska, M. (2017). Displacement analysis of the human knee joint based on the spatial kinematic model by using vector method. Acta Mech. Autom. 11. 4. DOI: 10.1515/ama-2017-0050.

16. Krzywicka, M., Grudziński, J., Tatarczak, J. \& Ścibisz, P. (2016). Study on the surface of the polymer insert of the knee replacement using pulsed thermography. Inz. Mater. 37. 2. DOI: $10.15199 / 28.2016 .2 .5$.

17. Szmajda, M. \& Bączkowicz, D. (2018). Use of incremental decomposition and spectrogram in vibroacoustic signal analysis 
in knee joint disease examination. Prze. Elektrotech. 94. 7. DOI: 10.15199/48.2018.07.41.

18. Wierzcholski, K. (2017). Geometrical structure for endoprosthesis surface lubrication and wear prognosis. J. KONES. 24. 4. DOI: $10.5604 / 01.3001 .0010 .3160$.

19. Korga, S., Makarewicz, A. \& Lenik, K. (2015) Methods of discretization objects continuum implemented in fem preprocessors. Adv. Sci. Technol. Res. J. 9. 28. DOI: 10.12913/22998624/60800.

20. Musalimov, V., Monahov, Y., Tamre, M., Robak, D., Sivitski, A., Aryassov, G. \& Penkov, I. (2018). Modelling of the human knee joint supported by active orthosis. Intern. J. Appl. Mech. Engine. 23. 1. DOI: 10.1515/ijame-2018-0007. 